\title{
Evaluation of the Response to Radiotherapy With Positron Emission Tomography/Computer Tomography in Head and Neck Carcinoma
}

\section{Baş Boyun Kanserlerinde Radyoterapi Sonrasında Tedavi Etkinliğinin Pozitron Emisyon Tomografi/Bilgisayarlı Tomografi İle Değerlendirilmesi}

\author{
Esra Kekilli' ${ }^{1}$, Candaş Tunalı ${ }^{2}$ \\ ${ }^{1}$ Dr Abdurrahman Yurtaslan Ankara Onkoloji Eğitim Ve Araștırma Hastanesi, Ankara \\ ${ }^{2}$ Çukurova Üniversitesi Tıp Fakültesi, Radyasyon Onkolojisi Anabilim Dalı, Adana
}

Dergiye Ulaşma Tarihi: 17.12.2018 Dergiye Kabul Tarihi:26.02.2019 Doi: 10.5505/aot.2019.47568

\section{ÖZET}

GÍRIŞ ve AMAÇ: Bu çalışmanın amacı baş boyun kanserli hastalarda radyoterapi ya da eşzamanlı kemoradyoterapi sonrası tedavi cevabının Pozitron EmisyonTomografi/Bilgisayarlı Tomografi ile değerlendirilmesidir.

YÖNTEM ve GEREÇLER: Nisan 2009 ile Nisan 2011 tarihleri arasında, kliniğimizde tedavi edilmiş baş boyun kanserli 36 hasta prospektif olarak çalışmaya dahil edilmiştir. Tüm hastalara tedavi öncesinde ve sonrasında Pozitron Emisyon Tomografi/Bilgisayarlı Tomografi görüntüleme yapılmıştır ve bu görüntülemede elde edilen maksimum standart tutulum değerleri incelenerek tedaviye yanıt değerlendirilmiştir. Hastalık evrelemesi yapılırken primer tümörden alınan biyopsilerin histopatolojik incelenmesi ve Pozitron Emisyon Tomografi/Bilgisayarlı Tomografi esas alınmıştır. Tümörlerin evrelemesi American Joint Committee on Cancer 6. baskıya göre yapılmıştır.

BULGULAR: Çalışmaya alınan 36 hastanın 32'si erkek (\% 88,9), 4'ü kadın (\% 11,1)'dır. Yaş ortalaması ise 57,5 (35-77) olarak saptanmıştır. Olgularımızın ortalama takip süresi 13,5 aydır. Hastaların tedavi öncesi Pozitron Emisyon Tomografi/Bilgisayarlı Tomografi ile ölçülen maksimum standart tutulum değerlerinin ortalaması 11 (3,5-23)'dir. Maksimum standart tutulum değeri 11'den büyük hastaların tedavi yanıtları küçük olan hastalara göre daha kötü bulunmuştur. Evrenin artışıyla standart tutulum değerinin arttığı ve standart tutulum değerinin tedavi sonunda erken evre hastalarda $(p=0,002)$, ileri evre hastalara kıyasla çok daha fazla gerilediği saptanmıştır $(\mathrm{p}<0,001)$.

TARTIŞMA ve SONUÇ: Bu çalışmada tedavi öncesi maksimum standart tutulum değeri yüksek hastaların tedavi yanıtlarının daha kötü olduğu ayrıca tedavi öncesi standart tutulum değerleri ve standart tutulum fark değerleri ile tedavi yanıtı arasında güçlü bir ilişkinin olduğu gösterilmiştir.

Anahtar Kelimeler: Baş boyun kanserleri, Pozitron Emisyon Tomografi/Bilgisayarlı Tomografi, standart tutulum değeri, tedavi cevabi.

\footnotetext{
ABSTRACT

INTRODUCTION: The aim of this study is to assessment of therapy response to radiotherapy or concurrent chemoradiotherapy in patients with head and neck carcinoma using with Positron Emission Tomography/Computer Tomography.

MATERIAL and METHODS: 36 head and neck cancer patients who were treated in our clinic between April 2009 and April 2011 were prospectively included this study. All patients were scanned with Positron Emission Tomography/Computer Tomography imaging before and after treatment and therapy response was evaluated by using standard uptake value max. Positron Emission Tomography/Computer Tomography results and biopsy that was taken from primary tumor as histopatologic assessing used for patients staging. This staging is based on American Joint Committee on Cancer 6.th edition.

RESULTS: Patients who were accepted this study were 32 male $(88,9 \%)$ and 4 female $(11,1 \%)$. The mean age of the patients was 57,5 (35-77) years. Mean follow up time was 13,5 months. Pretreatment mean of standard uptake value max was 11 . High standard uptake values $\max (>11)$ predicted significantly worse treatment response as compared with low standard uptake value max $(<11)$. Standard uptake value max was increased as the stage increased. At the end of the treatment standard uptake value max in early stage patients $(0,002)$ was much more regressed than advanced stage patients $(<0,001)$.
} 
DISCUSSION AND CONCLUSION: In this study demonstrated that the patients with pretreatment high standard uptake value max had poorer treatment response. This study showed that pretreatment and the difference standard uptake values max are strong related with therapy response.

Keywords: Head and neck cancer, Positron Emission Tomography/Computer Tomography, standard uptake value, therapy response.

\section{GİRIS}

Baş ve boyun kanseri dünya çapında sekizinci en s1k görülen kanser olup, yaklaş1k 500.000 yeni vaka tanı almaktadır (1). Erken teşhis ve doğru evreleme, tedavi stratejisinin belirlenmesinde kritik öneme sahip olup prognozu ciddi bir şekilde etkilemektedir. Baş boyun kanserli hastaların yaklaşı \%60'1 metastatik olmayan lokal ileri hastalık ile başvurmaktadır. Lokal ileri veya unrezektabl hastalıkta radyoterapi veya kemoradyoterapi önemli rol oynar (2). Primer tedaviden sonra lokal ileri baş boyun kanserli hastaların $\% 50$ 'den fazlası lokal bölgesel rekürrens ya da uzak metastaz yaparlar $(3,4)$, tedavi sonras1 dikkatli takip önemlidir (5). Tümörün belirlenmesi, evrelemesi, tedavi sonrası yeniden evrelemesi ve tedavi yanıtının değerlendirilmesindeki yararlılıkları nedeniyle onkolojik görüntülemeler baş boyun bölgesi kanserlerinde önemli bir yere sahiptir. Özellikle baş boyun kanserli hastaların takibinde, tedavi sonrası rezidüel ve nüks hastalığın tanısı oldukça zordur. Görüntülemenin önemli bir rol oynadığ evreleme, prognozu saptamada ve uygun bir tedavi stratejisi belirlemede kritiktir. Bilgisayarlı tomografi ve manyetik rezonans primer tümörün uzanımını değerlendirmede kullanılmaktadır. Oysa Pozitron Emisyon Tomografi/Bilgisayarl1 Tomografi (PET/BT) tanı anında evrelemede lokal, bölgesel hastalığı, uzak metastazı belirlemede; tedavi cevabını değerlendirmede; takipte klinik semptomlarla şüphelenildiğinde rekürrensi ve metastazı belirlemede merkezi bir rol oynar (6).

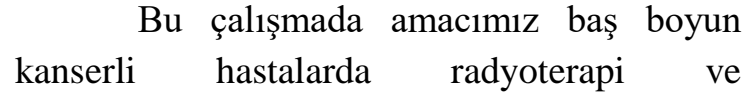

kemoradyoterapi sonrasi tedavi cevabının PET/BT ile değerlendirilmesidir.

\section{GEREÇ ve YÖNTEM}

Çukurova Üniversitesi Radyasyon Onkolojisi Anabilim Dalı'nda Nisan 2009 ile Nisan 2011 tarihleri arasında tedavi edilmiş baş boyun kanserli hastalar prospektif olarak çalışmaya dahil edilmiştir. Çalışmaya dahil edilen tüm hastalar tedavi öncesinde ve sonrasında hastanemiz Nükleer Tıp Anabilim Dalı'nda PET/BT ile değerlendirilmiştir. Çalışmamız için Çukurova Üniversitesi Tıp Fakültesi Etik Kurul Komitesinden 2/3 karar numarası ile 01.10.2009 tarihinde etik kurul izni alınmıştır.

Larinks, oral kavite ve tükrük bezi kanserli küratif tedavi amaçlanan 36 hasta çalışmaya alınmıştır. Hastaların hiç birinde tanı anında uzak metastaz yoktur. Bu hastaların tedavi öncesi ve sonrası olmak üzere iki kez PET/BT görüntüleme ile elde edilen maksimum standart tutulum değerleri (SUVmax) incelenerek tedaviye yanit değerlendirilmiştir. Bunların dışında hastaların yaş, cinsiyet, tümör histolojisi, başlangıç evresi, kemoterapi alıp almadı̆̆ı, operasyon geçirip geçirmediği, metastazının olup olmadığ 1 , radyoterapi dozu, performans durumları kaydedilmiştir. Hastalık evrelemesi yapılırken primer tümörden alınan biyopsilerin histopatolojik incelenmesi ve PET/BT esas alınmıştır. Tümörlerin evrelemesi American Joint Commitee on Cancer (AJCC) 6. baskiya göre yapilmıştır.

Çalışmaya kabul edilen hastaların PET/BT görüntülemeleri hastanemiz Nükleer Tıp Anabilim Dalı'nda “ Siemens, Biograph 6 " marka tarayıcı ile elde edildi. Tüm hastaların yaklaşık 6 saatlik açlık sonrası kan şekerleri $60-150 \mathrm{ng} / \mathrm{dl}$ arasinda olanlara, $12-14 \mathrm{mCi}$

Adress for correspondence: Esra Kekilli, Mehmet Akif Ersoy Mahallesi, 06200 Yenimahalle/Ankara 06200 Ankara - Türkiye

e-mail: ekekilli@ hotmail.com

Available at www.actaoncologicaturcica.com

Copyright $\odot$ Ankara Onkoloji Hastanesi 
Flor-18 Fluoro deoksi Glukoz (FDG) intravenöz enjeksiyonundan 1-1,5 saat sonra supin pozisyonda kollar yukarda kafadan femur proksimaline kadar olan bölge görüntü alanına girecek şekilde kesitler elde edildi. Görüntüler tüm vücut projeksiyonu ile koronal, transaxial ve sagittal planlarda kesitler alınarak değerlendirildi.

Tüm hastaların radyoterapisi 3 boyutlu konformal tedavi cihazı olan, Varian DHX lineer hizlandirıci ile $6 \mathrm{MV}$ foton enerjisi kullanılarak yapılmıştır. Tedaviye başlamadan önce bilgisayarlı planlama için Siemens Somatom Emotion marka simulator ile hasta supin pozisyonda sabitleyici termoplastik maske hazırlığ Tomografi görüntüleri elde edilmiştir. Tedavi planlamasinda konvansiyonel fraksiyon ile haftada 5 fraksiyon olacak şekilde: erken evre larinks kanseri tanılı hastalarımıza primer tümör volümüne 63-66 Gy, (1,8-2 Gy/fx/gün); opere larinks karsinomlu hastalarımıza postoperatif tümör yatağına $60-66 \mathrm{~Gy},(1,8-2$ Gy/fx/gün); patolojik lenf nodu pozitifliği olan lenf nodu istasyonlarına 60 Gy, $\quad(1,8-2$ Gy/fx/gün); elektif nodal istasyonlara 46-54 Gy (1,8-2 Gy/fx/gün) radyoterapi doz reçetelemesi yapıldı. Oral kavite tümör tanılı hastalarımıza primer tümör volümü ve tutulu lenf nodu alanlarına 60-66 Gy(1,8-2 Gy/fx/gün) definitif radyoterapi planı yapıldı. Opere oral kavite tümör tanılı hastalarımıza postoperatif tümör yatağı ve ekstrakapsüler uzanımı olan lenf nodu istasyonlarına $66 \mathrm{~Gy}$, (1,8-2 Gy/fx/gün) postoperatif yatak, preoperatif ipsilateral veya kontralateral lenfadenopati ve yüksek riskli subklinik hastalık bölgesine $60 \mathrm{~Gy}(1,8-2 \mathrm{~Gy} / \mathrm{fx} / \mathrm{gün})$ ve tutulu olmayan boyunda ipsilateral ve/veya kontralateral nodal seviyelerle birlikte düşük riskli subklinik alana 46-54 Gy (1,8-2 Gy/fx/gün) radyoterapi doz reçetelemesi yapıldı. Tükrük bezi tümörlü opere hastalarımıza postoperatif tümör yatağına 60 Gy (1,8-2 Gy/fx/gün) ve klink patoloik lenf nodu istasyonlarına ve elektif ipsilateral lenf nodu istasyonlarina 46-50 Gy $\quad(1,8-2$ $\mathrm{Gy} / \mathrm{fx} /$ gün) radyoterapi doz reçetelemesi ile plan yapıldı. Eş zamanlı kemoterapi uygulanan hastalarımıza haftalık sisplatin $\left(40 \mathrm{mg} / \mathrm{m}^{2}\right)$ rejimi uygulandı. Hastalar tedavi sonrası 3'er aylık aralıklarla izlenmişlerdir. Tedaviden sonraki ilk kontrol ortalama 3 ay sonunda yapılmış olup ilk kontrolde PET/BT çektirilmiştir. Olguların tedavi yanıtı: primer tümör alanında veya başka bir alanda hesaplanmış olup, FDG tutulumunun olmaması tam yanıt; primer tümör alanında FDG tutulumunun $\% 50$ ve daha fazla azalmas 1 parsiyel yanıt; FDG tutulumunda artış veya başka bir bölgede tutulum olması ise progresif hastalık olarak kabul edilmiştir.

\section{İstatistiksel Analiz}

Verilerin istatistiksel analizinde SPSS 18,0 paket programı kullanıldı. Kategorik ölçümler sayı ve yüzde olarak, sayısal ölçümlerse ortalama ve standart sapma (gerekli yerlerde ortanca ve minimum - maksimum) olarak özetlendi. Kategorik ölçümlerin gruplar arasında karşılaştırılmasında Ki Kare test istatistiği kullanıldı. Normal dağılım göstermeyen sayısal ölçümlerin iki grup arasında karşılaştırmasında Mann Whitney U testi kullanıldı. Normal dağılım göstermeyen sayısal ölçümleri ikiden fazla grup arasında genel karşılaştırmada Kruskal Wallis testi kullanıldı. Tüm testlerde istatistiksel önem düzeyi 0.05 olarak alındı.

\section{BULGULAR}

Çalışmaya alınan 36 hastanın 32'si erkek (\% 88,9), 4'ü kadın (\% 11,1)'dır. Hastalar çalışmaya alındıkları sırada yaşları 35 ile 77 (ortalama 57,5) arasında değişmekteydi. Tüm hastalar 3'er aylık aralıklarla izlenmiş olup; ortalama takip süresi 13,5 aydır. Tüm hastaların özellikleri tablo 1'de sunulmaktadır. Çalışmaya dahil edilen hastaların 8 (\% 22.2)'i sadece radyoterapi, 13 (\% 36.2)'ü eş zamanlı 
kemoradyoterapi, 8 (\% 22.2)'i cerrahi sonras1 adjuvan radyoterapi, 7 (\% 19.4)'si cerrahi sonrası eş zamanlı kemoradyoterapi ile tedavi edilmiştir. Hastalarımızın tedavi yanıtları, radyoterapi bitiminden 3 ay sonra yapilan PET/BT görüntüleme sonuçlarına göre değerlendirildi. 23 hastada tam cevap, 5 hastada lokal nüks, 6 hastada hem lokal nüks hem uzak metastaz, 2 hastada ise sadece uzak metastaz saptanmıştır.

Uzak metastaz saptanan tüm hastalarımızda metastaz bölgesi akciğerdir. Hastaların primer tümör bölgelerine göre tedavi yanıtı değerlendirilmiştir. Primer larinks olan hastaların $18(\% 69,2)$ 'i tam yanıt, 2 (\% $7,6)$ 'si parsiyel yanıt, $6(\% 23,1)$ 's1 progresif hastalık olarak saptanmıştır. Oral kavite yerleşimli tümörlerin $3(\% 37,5)$ 'ü tam yanıt, 2 (\% 25)'si parsiyel yanıt, 3 (\% 37.5)'ü progresif hastalık olarak saptanmıştır. Tükrük bezi tümörlü 2 hasta ise tam yanıt vermiştir. İstatistiksel anlamlılık bulunmamıştır $(\mathrm{p}=0,387)$.

Takiplerde 8 hastamız kaybedilmiştir. Hastaların tedavi öncesi PET/BT ile ölçülen SUVmax değerlerinin en düşüğü 3,5 . en yükseği 23, ortalaması 11 olarak bulunmuştur. Hastaların tedaviden sonraki 3. Ayda çekilen PET/BT'de ölçülen SUVmax değerlerinin en düşüğü 0 en yükseği 32, ortalaması 6 olarak bulunmuştur. Grafiği şekil 1'de gösterilmektedir.

Hastaların evrelerine göre tedavi cevabı değerlendirildiğinde; erken evre hastaların tamaminda tam cevap; ileri evre hastaların ise 12 (\% 45,8)'i tam cevap, 4 (\% 16,7)'ü parsiyel cevap, $9(\% 37,5)$ 'u progresif hastalık olarak bulunmuştur.

Tedavi sonrasi SUVmax ve tedavi öncesi ile sonrası farkı hesaplanarak elde edilen fark SUVmax' a göre tedavi yanttları incelenmiştir. Analiz sonuçlarına göre tedavi sonras1 SUVmax ortalamas1 tam yanıt veren hastaların $0.85 \pm 2$; parsiyel yanit verenlerin $5.75 \pm 4.27$; progrese olan hastaların $10,53 \pm$ 9,5 bulunmuştur $(\mathrm{p}<0.001)$. Fark SUV max ortalamas1 tam yanit verenlerin $-8,84 \pm 5,3$; parsiyel yanit verenlerin $-8,97 \pm 5,6$; progrese olanların $-2,2 \pm 9$ bulunmuştur $(\mathrm{p}=0.067)$. Hastaların tedavi öncesi SUVmax ile tedavi sonras1 SUVmax değerlerinin fark1 alınarak hesaplanan fark SUVmax'ın tedaviye verdikleri yanıtla ilişkisi aşağıdaki grafikte gösterilmiştir (şekil 2).

Hastaların tedavi öncesi PET/BT ile elde edilen SUVmax değerleri ortalama değerden yüksek ve düşük olanlar şeklinde gruplanarak, tedavi yanitları değerlendirilmiştir. Çalışmamıza dahil edilen 36 hastanın tedavi öncesi SUVmax değerlerinin ortalaması 11 olarak bulunmuştur. Hastaların \%63,9'unda bu değer 11'in altında, $\% 36,1$ 'inde 11'in üstünde saptanmıştır. SUVmax ortalama değeri 11'den düşük olan hastaların tedaviye tam yanıt verdikleri saptanmıştır $(\mathrm{p}=0,154)$.

Hastalarımızın evresi ile SUVmax değerleri arasındaki ilişki incelenmiş olup evrenin artışı ile SUVmax ortalama değerlerinin de arttığı saptanmıştır. Hastaların evre gruplarına göre tedavi öncesi ve sonras1 SUVmax değerleri ve bu iki değer arasındaki değişikliğin yüzdesi incelendiğinde her iki grupta da tedavinin etkin olduğu görülmüsşür. Ortalama SUVmax değeri tedavi sonunda erken evre hastalarda ilk değerin \% 3,3'üne $(\mathrm{p}=0,002)$, ileri evre hastalarda ise $\% 47,8$ 'ine $(\mathrm{p}<0,001)$ gerilediği görülmüştür. Tedavi sonrasında SUVmax değerindeki bu azalma istatistiksel olarak anlamlı bulunmuştur ve tablo 2'de görülmektedir.

\section{TARTIŞMA}

Baş boyun kanserli hastalarda prognostik faktörlerin doğru belirlenmesi hastaların etkin bireysel tedavilerinde yardımc1 olacaktır. Bu nedenle araştırmalar yeni prognostik faktörlerin belirlenmesi üzerine yoğunlaşmıştır. Birçok çalışmada PET/BT'de elde edilen standart tutulum değeri (SUV) değerinin prognoz üzerine etkisi hala 
belirsizlikler gösterse de iki metaanalizde baş boyun kanserlerinde prognoz üzerine SUV değerinin etkisi gösterilmiştir. Bunlardan ilki; primer bölgede tedavi öncesi ölçülen SUV'un prognostik değeri incelendiğinde yüksek SUVmax değerlerinin kötü genel sağkalım, hastalıksız sağkalım ve lokal kontrolle anlamlı ilişkili bulunmuştur (7). İkincisinde araştırmacılar primer tümördeki artmış SUV değerlerinin kötü bir prognostik faktör olduğu ve lokal kontrolü, hastalıksız sağkalımı, genel sağkalımı tahmin etmede potansiyel bir değere sahip olduğu sonucuna varmışlar (8). Bizim çalışmamızda da takip süresi kısa olsa da baş boyun kanserlerinde FDG-PET/BT SUVmax'ın bağımsız, noninvaziv prognostik bir araç olduğu öngörülebilir. Tedavi öncesi SUVmax ortalama değeri 11'den düşük olan hastaların tedaviye tam yanıt verdikleri görülmüştür. Hastaların \%63,9'unde bu değer 11'in altında, \%36,1'inde 11'in üstünde saptanmıştır. SUVmax ortalama değeri 11'den düşük olan hastaların tedaviye tam yanıt verdikleri saptanmıştır $(\mathrm{p}=0,154)$.

Bir başka çalışmada da primer tümöre ait SUV max değeri aynı çalışma için belirlenen medyan değerin altındaki hastalarda daha iyi lokal bölgesel kontrol ve progresyonsuz sağkalım elde edildiği görülmüş. SUV temelli ölçümlerin kısıtlamaları ve küçük örnekler olsa da PET/BT'nin evrelemeyi tamamlayıc1 bir değerinin olduğu açıktır (9).

Radyoterapi ile tedaviden sonra, PET/BT iyi yanıt verenleri tanımlamak ve boyun diseksiyonundan kaçınmak için kullanılabilir. Tedavi sonrası PET/BT yapılan Baş-boyun kanserli hastaların değerlendirildiği çalışmaların gözden geçirildiği bir derlemede; tedavi sonrası yüksek SUV max değeri olan hastaların kötü sonuçlarla korele olduğu görülmüş.(10). Bizim çalışmamızın sonuçlarına göre tedavi sonrası SUVmax ortalamas1 progrese olan grupta daha yüksek saptanmıştır. Tam yanıt veren hastaların $0.85 \pm$ 2; parsiyel yanit verenlerin $5.75 \pm 4.27$; progrese olan hastaların 10,53 $\pm 9,5$ bulunmuştur $(\mathrm{p}<0.001)$.

Tedavi öncesi ve tedaviden 8 hafta sonra PET/BT yapılan 98 hastanın değerlendirildiği bir başka çalışmada yazarlar PET/BT'de tedavi sonras1 SUV max $\leq 6 \mathrm{ng} / \mathrm{ml}$ olan ve tedavi öncesi ve sonrasi arasındaki SUV max \% değişikliklerinin hastalıksız sağkalım için belirleyici olarak bulmuşlardır (11). Bizim hastalarımızda ise evre gruplarına göre tedavi öncesi ve sonrası SUVmax değerleri ve bu iki değer arasındaki değişikliğin yüzdesi incelendiğinde; ortalama SUVmax değeri tedavi sonunda erken evre hastalarda ilk değerin\% 3,3'üne $(\mathrm{p}=0,002)$, ileri evre hastalarda ise \% 47,8'ine $(p<0,001)$ gerilediği görülmüştür.

Çalışmamızın, vaka sayısının az olmas1, heterojen gruplar içeriyor olması ve kısa süreli takip gibi limitasyonları bulunmaktadır.

\section{SONUÇ}

Yayınlanmış pek çok çalışmaya benzer şekilde, bizim çalışmamızda da tedavi öncesi SUVmax medyan değeri yüksek olan hastaların tedavi yanıtlarının daha kötü olduğu ve tedavi öncesi ve sonrası saptanan SUVmax değerleri arasındaki yüzde değişimlerin tedavi yanıtı için belirleyici olabileceği gösterilmiştir. 
Tablo 1. Hasta Özellikleri

\begin{tabular}{|c|c|}
\hline & Say1 (\%) \\
\hline Toplam hasta sayıs & 36 \\
\hline \multicolumn{2}{|l|}{ Cinsiyet } \\
\hline Kadın & $4(11,1)$ \\
\hline Erkek & $32(88,9)$ \\
\hline Yaş ortalaması & 57,5 \\
\hline \multicolumn{2}{|l|}{ Tanı } \\
\hline Larinks & $26(72,2)$ \\
\hline Ağız boşluğu & $8(22,3)$ \\
\hline Tükrük bezi & $2(5,6)$ \\
\hline \multicolumn{2}{|l|}{ Histopatoloji } \\
\hline Epidermoid & $31(86,1)$ \\
\hline Bazal hücreli & $2(5,6)$ \\
\hline Mukoepidermoid & $2(5,6)$ \\
\hline Asinik hücreli & $1(2,8)$ \\
\hline \multicolumn{2}{|l|}{ Evre } \\
\hline I & $6(17)$ \\
\hline II & $5(14)$ \\
\hline III & 11(30) \\
\hline IV & $14(39)$ \\
\hline Biyopsi yapılan & $21(58,3)$ \\
\hline Opere edilen & $15(41,7)$ \\
\hline \multicolumn{2}{|l|}{ KT } \\
\hline Alan & $20(55,6)$ \\
\hline Almayan & $16(44,4)$ \\
\hline \multicolumn{2}{|l|}{ Performans durumu } \\
\hline$\geq 80$ & $26(72,2)$ \\
\hline$<80$ & $10(27,8)$ \\
\hline
\end{tabular}

Adress for correspondence: Esra Kekilli, Mehmet Akif Ersoy Mahallesi, 06200 Yenimahalle/Ankara 06200 Ankara - Türkiye e-mail: ekekilli@hotmail.com

Available at www.actaoncologicaturcica.com

Copyright $\odot$ Ankara Onkoloji Hastanesi 
Tablo 2. Tedavi öncesi ve sonrası SUVmax değerleri ve \% değişim değerlerinin evre ile ilişkisi

\begin{tabular}{|c|c|c|c|c|}
\hline & $\begin{array}{c}\text { Tedavi öncesi } \\
\text { SUVmax } \\
\text { Ort } \pm \text { sd } \\
\text { Med (min-max) }\end{array}$ & $\begin{array}{c}\text { Tedavi sonrasii } \\
\text { SUVmax } \\
\text { Ort } \pm \text { sd } \\
\text { Med (min-max) }\end{array}$ & $\begin{array}{c}\% \text { değişim } \\
\text { Ort } \pm \text { sd } \\
\text { Med (min-max) }\end{array}$ & $\mathrm{p}$ \\
\hline Erken evre & $\begin{array}{c}9.1 \pm 4,83 \\
7,9(3,5-20)\end{array}$ & $\begin{array}{c}0,33 \pm 1,15 \\
0(0-4)\end{array}$ & $\begin{array}{c}3,3 \pm 11,6 \\
0(0-40)\end{array}$ & 0,002 \\
\hline İleri evre & $\begin{array}{c}12 \pm 4,93 \\
12,25(3,6-23)\end{array}$ & $\begin{array}{c}5,56 \pm 7,38 \\
4,5(0-34)\end{array}$ & $\begin{array}{c}47,8 \pm 56,6 \\
39,3(0-212)\end{array}$ & $<0,001$ \\
\hline
\end{tabular}

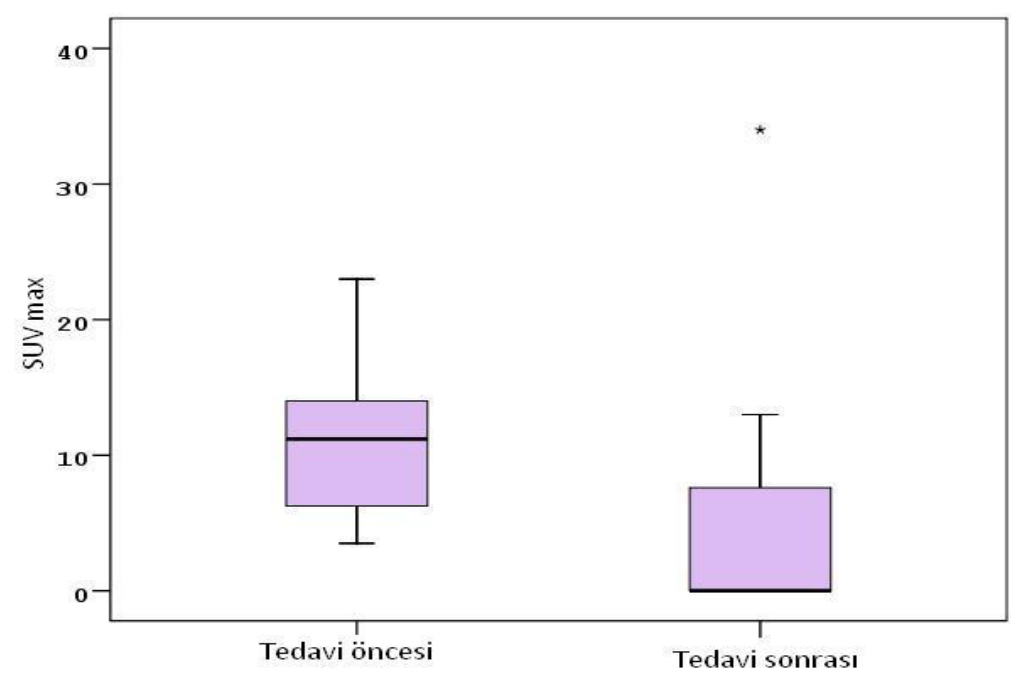

Şekil 1. Hastaların tedavi öncesi ve sonrası SUVmax değerleri grafikte gösterilmiştir. * ile belirtilen değer 32'dir. 


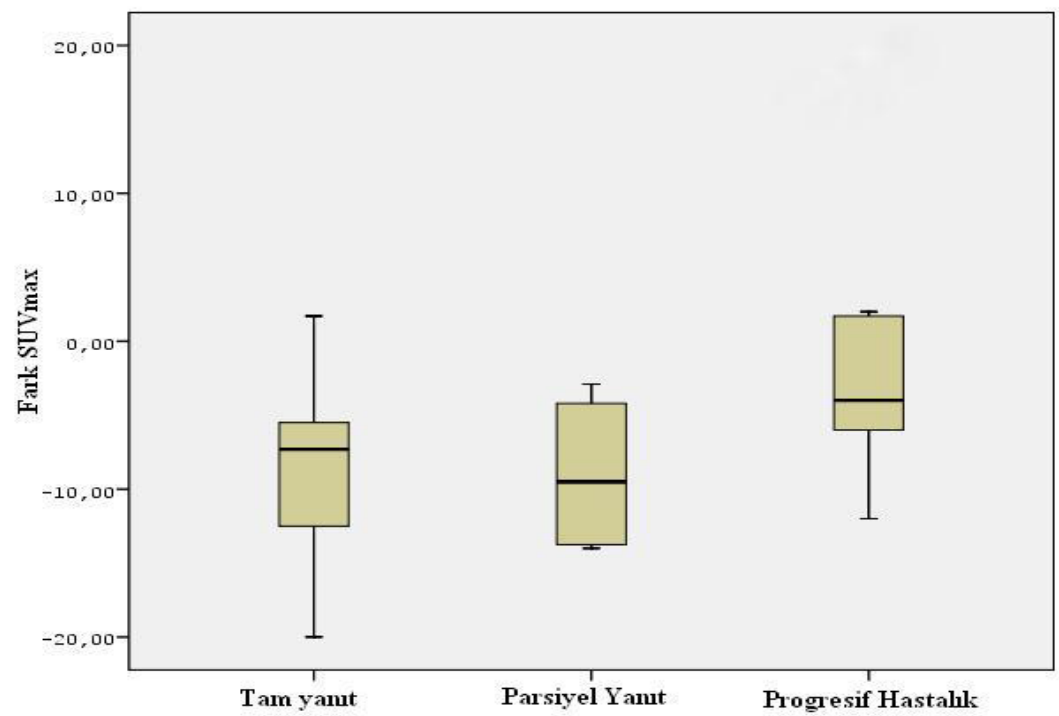

Şekil 2. SUVmax farkı ile tedavi yanıt ilişkisi

\section{REFERANSLAR}

1. Torre LA, Bray F, Siegel RL, Ferlay J, LortetTieulent J, and Jemal A: Global cancer statistics, 2012. CA Cancer J Clin 2015; 65: pp. 87-108

2. Kim S, Oh S, Kim JS et al. Prognostic value of FDG PET/CT during radiotherapy in head and neck cancer patients. Radiat Oncol J. 2018;36(2):95-102.

3. Cooper JS, Pajak TF, Forastiere AA et al. Postoperative concurrent radiotherapy and chemotherapy for high-risk squamous-cell carcinoma of the head neck. $N$ Engl J Med. 2004;350(19):1937-44.

4. Tobias JS,Monson K, Gupta $\mathrm{N}$ et al. Chemoradiotherpy for locally advanced head and neck cancer: 10-year follow-up of the UK head and neck (UKHAN1) trial. Lancet Oncol. 2010;11(1):66-74.

5. Kim SA, Roh JL, Kim JS et al. ${ }^{18}$ F-FDG PET/CT surveillance fort he detection of recurrence in patients with head and neck cancer. European Journal of Cancer. 2017(17):62-70.

6. Goel R, Moore W, Sumer B, Khan S, Sher D, Subramaniam RM. Clinical practice in PET/CT fort he management of head and neck squamous cell cancer. AJR. 2017;209:289-303.
7. Xie P, Li M, Zhao H, Sun X, Fu Z, Yu J. F-FDG PET or PET/CT to evaluate prognosis for head and neck cancer:a meta analysis. J Cancer Res Clin Oncol. 2011;137(7):1085-93.

8. Zhang B,Li X, Lu X. Standardized uptake value is of prognostic value for outcome in head and neck squamous cell carcinoma. Acta Otolaryhgol. 2010;130:756-62.

9. Shwartz DL, Harris J, Yao M et al. Metabolic tumor volüme as a prognostic imaging-based biomarker for head and neck cancer-pilot results from RTOG 0522. Int J Radiat Oncol Biol Phys. 2015 March 15;91(4):721-729.

10. Castelli J, Bari BD, Depeursinge A et al. Overview of the predictive value of quantitative 18-FDG PET in head and neck cancer treated with chemoradiotherapy. Critical Reviews in Oncology/Hematology. 201;108:40-51.

11. Moeller BJ, Rana V, Cannon BA et al. Prospective imaging assessment of mortality risk after head and neck radiotherapy. Int J. Radiat. Oncol. Biol. Phys. 2010;78(3):667-674. 